\title{
Insulin Resistance, Obesity, Hypertension, and Renal Sodium Transport
}

\author{
Shoko Horita, George Seki, Hideomi Yamada, Masashi Suzuki, Kazuhiko Koike, \\ and Toshiro Fujita
}

Department of Internal Medicine, Faculty of Medicine, The University of Tokyo 7-3-1, Hongo, Bunkyo, Tokyo 113-8655, Japan

Correspondence should be addressed to George Seki, georgeseki-tky@umin.ac.jp

Received 14 January 2011; Accepted 16 February 2011

Academic Editor: Kazuko Masuo

Copyright (C) 2011 Shoko Horita et al. This is an open access article distributed under the Creative Commons Attribution License, which permits unrestricted use, distribution, and reproduction in any medium, provided the original work is properly cited.

\begin{abstract}
Sodium transport through various nephron segments is quite important in regulating sodium reabsorption and blood pressure. Among several regulators of this process, insulin acts on almost all the nephron segments and is a strong enhancer of sodium reabsorption. Sodium-proton exchanger type 3 (NHE3) is a main regulator of sodium reabsorption in the luminal side of proximal tubule. In the basolateral side of the proximal tubule, sodium-bicarbonate cotransporter (NBCe1) mediates sodium and bicarbonate exit from tubular cells. In the distal nephron and the connecting tubule, epithelial sodium channel (ENaC) is of great importance to sodium reabsorption. $\mathrm{NHE}$, NBCe1, and $\mathrm{ENaC}$ are all regulated by insulin. Recently with-no-lysine (WNK) kinases, responsible for familial hypertension, stimulating sodium reabsorption in the distal nephron, have been found to be also regulated by insulin. We will discuss the regulation of renal sodium transport by insulin and its roles in the pathogenesis of hypertension in insulin resistance.
\end{abstract}

\section{Introduction}

Obesity is frequently accompanied with hypertension [1]. Obesity is, at the same time, closely related to hyperinsulinemia and insulin resistance [2]. While the precise mechanism of hypertension in insulin resistance remains to be clarified, the activation of sympathetic nerve system, the disorders dysregulation of central nerve system including leptin, and the activation of renin-angiotensin system are generally thought to be involved [1]. Although insulin has powerful stimulatory effects on renal sodium transport, it remains controversial whether hyperinsulinemia itself is a cause of hypertension.

Acute studies suggest that hyperinsulinemia may cause sodium retention and increased sympathetic activity, which will be an important cause of hypertension [3]. On the other hand, hyperinsulinemia due to insulinoma or chronic insulin infusion into animals do not significantly elevate blood pressure $[4,5]$. Moreover, insulin itself has vasodilatory actions [6], which is dependent on nitric oxide [7]. Thus, the relationship between hyperinsulinemia and hypertension is not obvious.
However, the influence of insulin on blood pressure may be altered in insulin resistance. For example, the insulininduced vasodilation is impaired due to defects in PI3kinase signaling in insulin resistance $[8,9]$. Moreover, several recent data suggest that the insulin-induced enhancement of renal sodium reabsorption is preserved or even enhanced in insulin resistance [10-12]. For example, Rocchini et al. showed that, in obese subjects with insulin resistance, urinary sodium excretion was decreased by insulin similarly as in nonobese subjects [11]. These considerations support a significant role of insulin-stimulated renal sodium transport in the pathogenesis of hypertension in insulin resistance. This review will focus mainly on the regulation of sodium reabsorption along the nephron segments by insulin and its roles in the blood pressure control. Figure 1 shows the main sodium transporters and regulators discussed in this review.

\section{Insulin Acting Sites upon Nephron}

It has been known for a long time, that insulin acts upon the whole nephron. Bourdeau et al. showed, using radioisotope technique that insulin is accumulated in the proximal tubule 
[13]. Nakamura et al. showed that insulin binds upon various segments of rabbit nephron, among which it binds strongest upon thick ascending limb of Henle's loop and distal convoluted tubule [14]. In rat nephron, Butlen et al. showed that insulin is accumulated strongest in the proximal tubule, second in the pars recta and distal convoluted tubule [15]. The way that insulin arrives at the nephron seems to be by two ways: one is by glomerular clearance, and the other is peritubular clearance [16]. The former is by glomerular filtration and subsequent reabsorption from tubular cells by endocytosis, the latter is diffusion from peritubular capillaries and subsequent binding to the receptor.

\section{Insulin and Renal Proximal Absorption}

Insulin uptake in the renal proximal tubule has been reported on animals such as rabbits [13], rats [17], and dogs [18]. Importantly, insulin has been known to enhance sodium reabsorption in the proximal tubule [19]. Insulin stimulates not only sodium but also volume absorption in the rabbit proximal convoluted tubule. Regarding these stimulatory effects, insulin acts only from the basolateral side of the tubule, not from the luminal side [20]. Proximal tubules reabsorb about seventy percents of total $\mathrm{Na}$ filtered from glomeruli. Though important regulatory mechanisms exist afterwards in the Henle's loop, distal tubule and connecting tubule, the stimulation of $\mathrm{Na}$ reabsorption from proximal tubules may well contribute to the increase of total fluid volume in the individual, leading to hypertension.

Gesek and Schoolwerth proved that insulin directly increases the $\mathrm{Na}^{+}-\mathrm{H}^{+}$exchanger type 3 (NHE3) activity in proximal tubules of rats [21]. This is important because NHE3 plays a major role in apical sodium entry in proximal tubules. Although the signaling pathway of insulin-mediated NHE3 activation remains unclear, Akt is known to play a critical role in the phosphoinositide 3-kinase- (PI3K-) mediated translocation of NHE3 into the apical membranes of proximal tubular cells [22-24]. The PI3K pathway has also chronic and posttranscriptional effects on the re-gulation of NHE3 mRNA in the proximal tubule cell $[20,25,26]$.

It has been shown that Na-K-ATPase is also a target of insulin, contributing to the increase of $\mathrm{Na}$ reabsorption $[27,28]$. Feraille et al. have showed that, in rat proximal convoluted tubule, insulin stimulates $\mathrm{Na}-\mathrm{K}$-ATPase activity [29]. Insulin is also known to stimulate the basolateral electrogenic $\mathrm{Na}-\mathrm{HCO}_{3}$ cotransporter (NBCe1), which plays a major role in sodium and bicarbonate exit from proximal tubular cells [30]. Therefore, insulin stimulates all the transporters involved in $\mathrm{Na}$ absorption from proximal tubules.

\section{Insulin and Other Renal Tubules}

4.1. Henle's Loop. Kirchner reported that insulin enhances chloride reabsorption in the Henle's loop of volumeexpanded rats [31]. This showed a possibility that insulin may stimulate $\mathrm{NaCl}$ reabsorption in Henle's loop. Later, in rabbit kidney, it was shown that insulin directly stimulates $\mathrm{NaCl}$ reabsorption in Henle's loop [32]. Moreover, it was suggested that $\mathrm{Na}-\mathrm{K}-2 \mathrm{Cl}$ cotransporter (NKCC2) and $\mathrm{Na}-\mathrm{K}-$ ATPase are also involved in this stimulation [33]. Tsimaratos et al. have clarified that C-peptide, the cleavage product of proinsulin, stimulates $\mathrm{Na}-\mathrm{K}$-ATPase in rat thick ascending limb, which is mediated via protein kinase C (PKC) $\alpha$ pathway [34]. They also showed that C-peptide activates $\mathrm{PKC} \alpha$, which then stimulates the phosphorylation of $\mathrm{Na}-\mathrm{K}-$ ATPase $\alpha$-subunit.

As about twenty percents of Na reabsorption is accomplished at Henle's loop, stimulation of $\mathrm{Na}$ reabsorption here should have a substantial impact on whole-body $\mathrm{Na}$ homeostasis.

4.2. Distal Tubule and Connecting Tubule. In late tubule, including distal and connecting tubules, it is widely known that insulin stimulates the activity of amiloride-sensitive epithelial sodium channel (ENaC) [35]. A study using kidney-derived cell line has shown that the activation of $\mathrm{ENaC}$ by insulin results from an increase of $\mathrm{ENaC}$ channel density at the membrane [36]. Moreover, insulin is known to stimulate Na-K-ATPase in this segment [37, 38]. Consistent with these findings, DeFronzo et al. found that hyperinsulinemia and hyperglycemia enhance sodium reabsorption from distal tubule [19]. Some studies showed that insulin stimulates sodium transport via a signaling cascade involving PI3K, 3-phosphoinositide-dependent protein kinase (PDK1), and serum/glucocorticoid-kinase 1 (Sgk1) $[39,40]$. In distal tubule, there are other transporters and kinases that are affected by insulin, such as with-no-lysine (WNK) kinases and sodium-chloride cotransporter (NCC), which we will discuss later.

Distal and connecting tubules regulate only about ten percents of total $\mathrm{Na}$ reabsorption in the nephron, but this process cannot be ignored as the final regulation of $\mathrm{Na}$ reabsorption.

\section{IRS1/2, Hyperinsulinemia, Insulin Resistance, and Hypertension}

Insulin receptor substrate (IRS) 1 was originally found through an attempt to find out the signal transduction system of insulin [41, 42]. IRS1 ${ }^{-/-}$mice, however, survived with only a mild insulin resistance, which led to the identification of IRS2 [43]. The structures of IRS1 and IRS2 are quite similar to each other [44], but the signaling pathway is different [45]. IRS1 and IRS2 knockout mice develop mental retardation and insulin resistance [46, 47]. IRS-1 and IRS-2 differ in the tissue expression, the mechanism of insulin resistance, and the association of $\beta$-cell hyperplasia [48]. Some IRSs have been found later but IRS1 and IRS2 are the most important among the IRS family.

Our group compared the effects of insulin on proximal tubule absorption in wild-type, IRS1 $1^{-/-}$and IRS2 $2^{-/-}$mice [49]. In wild-type mice, insulin significantly stimulated Na-coupled $\mathrm{HCO}_{3}{ }^{-}$absorption from proximal tubule. In IRS1 ${ }^{-1-}$ mice, the stimulation of $\mathrm{HCO}_{3}{ }^{-}$absorption by insulin was preserved, but it was significantly attenuated in IRS2 ${ }^{-/-}$mice. Moreover, the Akt phosphorylation induced 


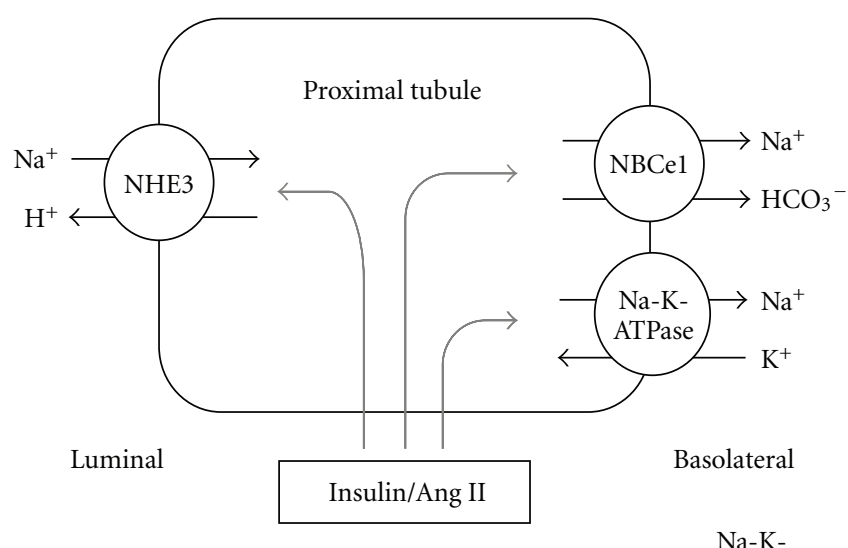

ATPase

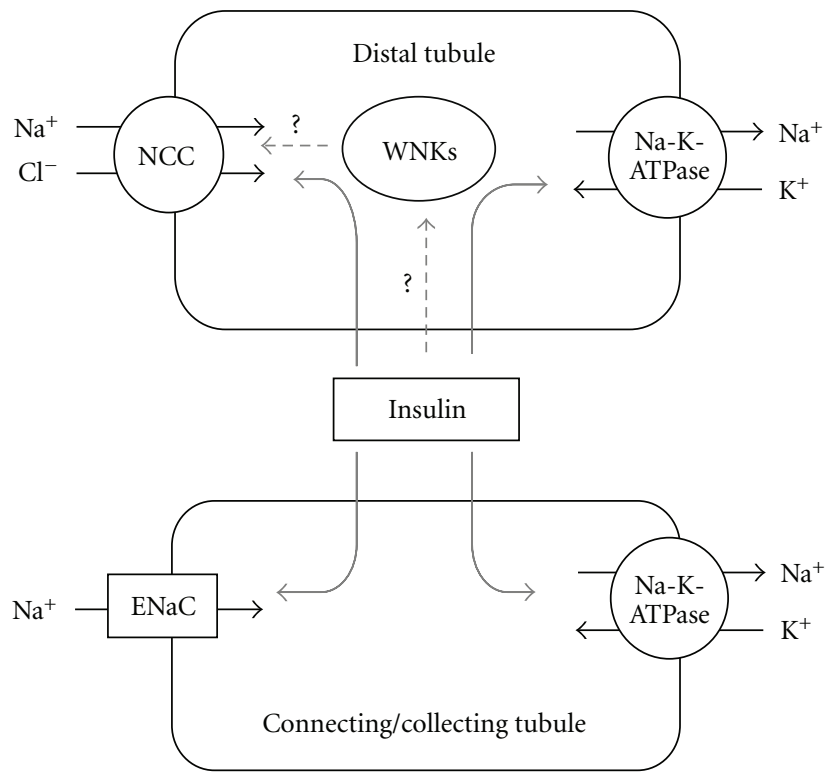

Figure 1: The main sodium transporters and regulators in the proximal tubule and distal and connecting/collecting tubules. In the proximal tubule, insulin and Ang II stimulate NHE3 at the luminal side, NBCe1, and Na-K-ATPase at the basolateral side. In the distal and connecting/collecting tubules, insulin stimulates ENaC and NCC in the luminal side, Na-K-ATPase at the basolateral side. Insulin may also indirectly stimulate NCC via WNK kinases.

by insulin stimulation, which mimicked the effect of insulin on proximal absorption, was preserved in $\mathrm{IRS1}^{-/-}$mice but significantly attenuated in IRS2 ${ }^{-/-}$mice. Consistent with a major role of IRS2 in the insulin-mediated transport stimulation in proximal tubules, the tyrosine phosphorylation of IRS2 by insulin was more prominent than that of IRS1. Importantly, signaling defects specific to IRS1 has been often reported in insulin resistance [50-53]. Thus, sodium retention through IRS1-independent way, facilitated by hyperinsulinemia, could be an important factor in the pathogenesis of hypertension in insulin resistance.

\section{Tumor Necrosis Factor (TNF) $\alpha$ and Renal Sodium Absorption}

$\mathrm{TNF} \alpha$ is a pleiotropic 157 -amino acid peptide cytokine. It is committed in various physiological reactions, such as inflammation, proliferation, cell differentiation, and cell death including cell apoptosis $[54,55]$. TNF $\alpha$ binds to TNF receptor (TNFR), which has two subtypes, called TNFR1 and TNFR2.

It has been proposed for a long that TNF $\alpha$ causes insulin resistance $[56,57]$. Uysal et al. reported that mice lacking TNF $\alpha$ function do not develop obesity-induced insulin resistance [58]. However, TNF $\alpha$ alone may be insufficient to induce insulin resistance [59].

Interestingly, there are controversial papers about the effect of $\mathrm{TNF} \alpha$ on sodium reabsorption. In C2BBe1 cells, derived from human intestinal epithelial cell line, TNF $\alpha$ was reported to reduce NHE3 expression via transcriptional regulation $[60,61]$. TNF $\alpha$ seems to reduce Sp1/Sp3 complex to bind to NHE3 promoter DNA via cAMP/PKA way. Relatively high concentrations, though within the physiological levels, of TNF $\alpha$ are also known to increase urine volume and 


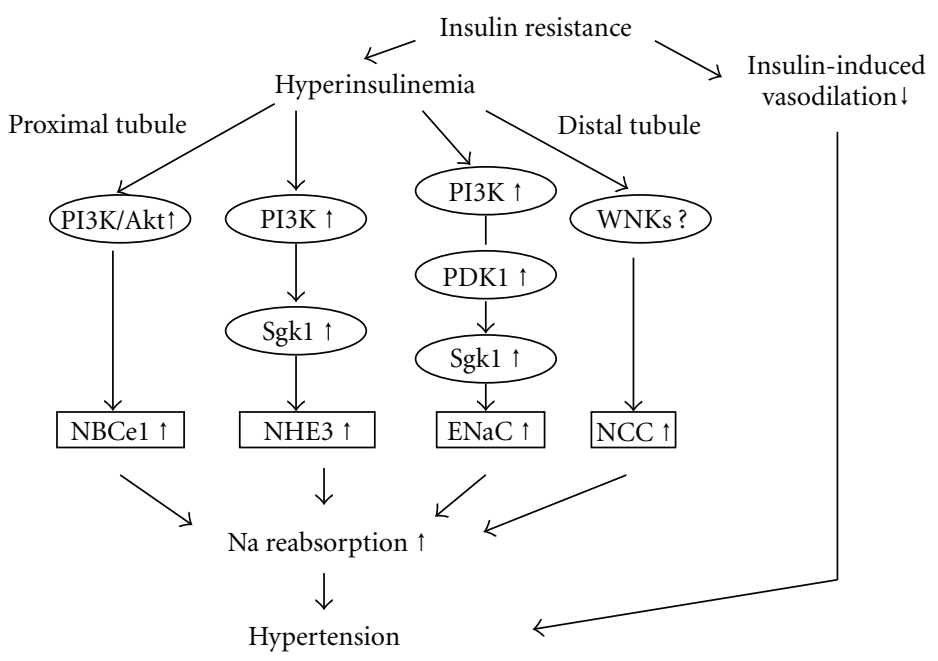

FIGURE 2: Mechanism of hypertension in insulin resistance. In insulin resistance, insulin-induced vasodilation is impaired. However, insulin induced sodium reabsorption through various nephron segments seems to be preserved or enhanced.

sodium excretion [62]. On the contrary, TNF $\alpha$ was reported to enhance sodium absorption from distal tubule in diabetic rats $[63,64]$. The stimulation of sodium uptake by TNF $\alpha$ was blocked by amiloride, an inhibitor of ENaC, and PD98059, an inhibitor of ERK. It seems that $\mathrm{TNF} \alpha$ acts on sodium status in a biphasic way: toward sodium excretion at high concentrations [65] and sodium retention at low concentrations. The effect of $\mathrm{TNF} \alpha$ on renal sodium reabsorption in the nondiabetic condition, however, remains to be clarified.

\section{Angiotensin II and Insulin Resistance}

Angiotensin II (Ang II) is important for its potent ability to raise blood pressure. In addition to the vascular effects, Ang II stimulates sodium absorption from the proximal tubule, acting on several transporters carrying sodium [66]. Renin-angiotensin system (RAS) is activated in insulinresistant state $[67,68]$. RAS activation, on the other hand, has been related to impaired insulin signaling and systemic insulin resistance in various tissues and organs [69]. RAS and insulin resistance are, therefore, believed to be closely related. Moreover, numerous clinical evidences with RAS inhibitors, such as ACE inhibitors and ARBs, show that the inhibition of RAS contributes to amelioration of insulin resistance, prevention of hypertension, and damage of tissues and organs.

Interestingly, Ang II is known to regulate proximal tubule transport in a biphasic way: stimulation by low (picomolar to nanomolar) concentrations and inhibition by high (nanomolar to micromolar) concentrations. Studies using Ang II type 1A receptor (AT1A) KO mice revealed that these effects of Ang II are mediated by AT1A [70, 71]. Interestingly, the ERK pathway mediates the stimulatory effect but not the inhibitory effect of Ang II in proximal tubules [72]. It is unknown whether the stimulatory effect of Ang II on proximal tubule transport is enhanced in insulin resistance.
On the other hand, hyperglycemic state was shown to stimulate Ang II expression in the proximal tubule derived cells [73]. This is mediated by p44/42 MAPK signal transduction system. Taken together, Ang II might act to enhance sodium reabsorption from proximal tubule in both acute and chronic phases of insulin resistance.

\section{Kidney and WNK, Hypertension, and Insulin}

WNK kinase was originally found as a kind of serinethreonine kinase with an atypical lysine placement [74]. Notably, mutations in WNK kinases cause Gordon's syndrome (pseudohypoaldosteronism type II (PHAII) or familial hyperkalemic hypertension $(\mathrm{FHH})$ ) [75]. This finding has led to investigating the regulation of WNK kinases and their effects on renal transporters, such as NCC (sodium chloride cotransporter) and NKCC (sodium-potassium-chloride cotransporter), in the context of blood pressure homeostasis.

WNKs have five subtypes: WNK1, WNK2, WNK3, and WNK4, and a transcriptional variant of WNK1, KS-WNK1 [76]. In the distal tubule cells, NCC reabsorbs sodium and chloride at the apical membrane. WNK4 reduces NCC amount at the plasma membrane at least in some conditions $[75,77-80]$. On the other hand, WNK4 is reported to enhance the NCC activity through its phosphorylation [81]. WNK1 does not affect NCC activity itself but suppresses WNK4 activity [78, 79]. KS-WNK1, which does not have kinase domain of WNK1, inhibits the WNK1 action on WNK4 $[82,83]$. WNK3 stimulates NCC activity in its active form, but exerts a negative effect in its inactive form $[84,85]$. In contrast to these distinct effects of individual WNKs on NCC, Heise et al. recently showed that WNKs 1, 3, and 4 all stimulate $\mathrm{ENaC}$ through serum glucocorticoid-induced kinase (SGK) 1, and that these stimulatory effects of WNKs are mediated by their $\mathrm{N}$-terminal sequences without kinase activity [86]. These results suggest that WNKs regulate NCC and $\mathrm{ENaC}$ through different mechanisms. 
TABLE 1: Effects of insulin on renal transporters, channels, or regulators.

\begin{tabular}{lcc}
\hline & Transporter/channel & Effects of insulin \\
\hline \multirow{3}{*}{ Proximal } & NBCe1 & Stimulation \\
& NHE & Stimulation \\
& Na-K-ATPase & Stimulation \\
\hline \multirow{2}{*}{ Henle } & NKCC & Stimulation \\
& Na-K-ATPase & Stimulation \\
\hline \multirow{4}{*}{ Distal } & ENaC & Stimulation \\
& NCC & Stimulation \\
& Na-K-ATPase & Stimulation \\
& WNK4 & $?$ \\
CNT & WNK1 & $?$ \\
\hline
\end{tabular}

Recently, there are some reports suggesting that insulin has influence on the activity of WNKs, which may have a role in the pathogenesis of salt-sensitive hypertension. For WNK1, Vitari et al. showed that WNK1 is a substrate of protein kinase $\mathrm{B} / \mathrm{Akt}$, a serine-threonine kinase known to be downstream of insulin signaling. This finding suggests that insulin may affect blood pressure by regulating WNK1 [87]. For WNK4, Sohara et al. have revealed that the WNK4 mutation (R1185C) induces excess phosphorylation of WNK4 S1190, which is a target phosphorylation site by insulin. They have also clarified that the phosphorylation of WNK4 S1190-OSR1/SPAK-NCC cascade is increased in the mice with hyperinsulinemia. These findings suggest that insulin regulates $\mathrm{Na}$ reabsorption from the distal tubule through WNKs and is involved in the pathogenesis of saltsensitive hypertension [88]. Ellison et al. showed that the WNK4-NCC pathway as well as the abundance of WNK4 was altered in the rat model of insulin resistance [89]. Huang and Kuo reported that insulin reduced the renal cortical WNK4 expression [90]. This would indirectly enhance NCC and $\mathrm{ENaC}$ [91]. Now, the interaction between WNK kinases and insulin is intensively investigated, so it is expected that, in the near future, the regulatory system of insulin and distal to connecting tubules will be much more clarified.

Table 1 is a summary of insulin action on the regulators of sodium transport in the nephron segment. Insulin acts mostly as an enhancer of sodium reabsorption. The effects of insulin on WNKs require further investigations. Figure 2 is a scheme about how insulin triggers the signal transduction downstream and leads to hypertension.

\section{Conclusion}

We have discussed the renal actions of insulin. Sodium transport along nephron segments is a key for regulating blood pressure and sodium metabolism, with great influence on cardiovascular management. There are several regulators along each segment of the nephron. Among them, insulin and its signal transduction system have outstanding features and important roles from the view of hypertension associated with insulin resistance. Moreover, WNKs seem to be important mediators of insulin actions on the distal nephron.

\section{References}

[1] J. E. Hall, D. A. Hildebrandt, and J. Kuo, "Obesity hypertension: role of leptin and sympathetic nervous system," American Journal of Hypertension, vol. 14, no. 6, pp. 103S-115S, 2001.

[2] B. B. Kahn and J. S. Flier, "Obesity and insulin resistance," Journal of Clinical Investigation, vol. 106, no. 4, pp. 473-481, 2000.

[3] G. M. Reaven and B. B. Hoffman, "A role for insulin in the aetiology and course of hypertension?" The Lancet, vol. 2, no. 8556, pp. 435-437, 1987.

[4] N. Tsutsu, K. Nunoi, T. Kodama, R. Nomiyama, M. Iwase, and M. Fujishima, "Lack of association between blood pressure and insulin in patients with insulinoma," Journal of Hypertension, vol. 8, no. 5, pp. 479-482, 1990.

[5] J. E. Hall, "Hyperinsulinemia: a link between obesity and hypertension?" Kidney International, vol. 43, no. 6, pp. 14021417, 1993.

[6] K. Hayashi, K. Fujiwara, K. Oka, T. Nagahama, H. Matsuda, and T. Saruta, "Effects of insulin on rat renal microvessels: studies in the isolated perfused hydronephrotic kidney," Kidney International, vol. 51, no. 5, pp. 1507-1513, 1997.

[7] H. O. Steinberg, G. Brechtel, A. Johnson, N. Fineberg, and A. D. Baron, "Insulin-mediated skeletal muscle vasodilation is nitric oxide dependent. A novel action of insulin to increase nitric oxide release," Journal of Clinical Investigation, vol. 94, no. 3, pp. 1172-1179, 1994.

[8] Z. Y. Jiang, Y. W. Lin, A. Clemont et al., "Characterization of selective resistance to insulin signaling in the vasculature of obese Zucker (fa/fa) rats," Journal of Clinical Investigation, vol. 104, no. 4, pp. 447-457, 1999.

[9] R. Li, H. Zhang, W. Wang et al., "Vascular insulin resistance in prehypertensive rats: role of PI3-kinase/Akt/eNOS signaling," European Journal of Pharmacology, vol. 628, no. 1-3, pp. 140147, 2010.

[10] D. Finch, G. Davis, J. Bower, and K. Kirchner, "Effect of insulin on renal sodium handling in hypertensive rats," Hypertension, vol. 15, no. 5, pp. 514-518, 1990.

[11] A. P. Rocchini, V. Katch, D. Kveselis et al., "Insulin and renal sodium retention in obese adolescents," Hypertension, vol. 14, no. 4, pp. 367-374, 1989.

[12] L. A. Sechi, "Mechanisms of insulin resistance in rat models of hypertension and their relationships with salt sensitivity," Journal of Hypertension, vol. 17, no. 9, pp. 1229-1237, 1999.

[13] J. E. Bourdeau, E. R. Y. Chen, and F. A. Carone, "Insulin uptake in the renal proximal tubule," American Journal of Physiology, vol. 225, no. 6, pp. 1399-1404, 1973.

[14] R. Nakamura, D. S. Emmanouel, and A. I. Katz, "Insulin binding sites in various segments of the rabbit nephron," Journal of Clinical Investigation, vol. 72, no. 1, pp. 388-392, 1983.

[15] D. Butlen, S. Vadrot, S. Roseau, and F. Morel, "Insulin receptors along the rat nephron: [125I] insulin binding in microdissected glomeruli and tubules," Pflugers Archiv European Journal of Physiology, vol. 412, no. 6, pp. 604-612, 1988.

[16] R. Rabkin, M. P. Ryan, and W. C. Duckworth, "The renal metabolism of insulin," Diabetologia, vol. 27, no. 3, pp. 351-357, 1984. 
[17] M. A. Cortney, L. L. Sawin, and D. D. Weiss, "Renal tubular protein absorption in the rat," Journal of Clinical Investigation, vol. 49, no. 1, pp. 1-4, 1970.

[18] R. Rabkin, N. M. Simon, S. Steiner, and J. A. Colwell, "Effect of renal disease on renal uptake and excretion of insulin in man," The New England Journal of Medicine, vol. 282, no. 4, pp. 182-187, 1970.

[19] R. A. DeFronzo, C. R. Cooke, and R. Andres, "The effect of insulin on renal handling of sodium, potassium, calcium, and phosphate in man," Journal of Clinical Investigation, vol. 55, no. 4, pp. 845-855, 1975.

[20] M. Baum, "Insulin stimulates volume absorption in the rabbit proximal convoluted tubule," Journal of Clinical Investigation, vol. 79, no. 4, pp. 1104-1109, 1987.

[21] F. A. Gesek and A. C. Schoolwerth, "Insulin increases $\mathrm{Na}^{+}-\mathrm{H}^{+}$ exchange activity in proximal tubules from normotensive and hypertensive rats," American Journal of Physiology, vol. 260, no. 5, pp. F695-F703, 1991.

[22] W. Lee-Kwon, D. C. Johns, B. Cha et al., "Constitutively active phosphatidylinositol 3-kinase and AKT are sufficient to stimulate the epithelial $\mathrm{Na}^{+} / \mathrm{H}^{+}$exchanger 3," Journal of Biological Chemistry, vol. 276, no. 33, pp. 31296-31304, 2001.

[23] W. Lee-Kwon, K. Kawano, J. W. Choi, J. H. Kim, and M. Donowitz, "Lysophosphatidic acid stimulates brush border $\mathrm{Na}^{+} / \mathrm{H}^{+}$exchanger 3 (NHE3) activity by increasing its exocytosis by an NHE3 kinase A regulatory protein-dependent mechanism," Journal of Biological Chemistry, vol. 278, no. 19, pp. 16494-16501, 2003.

[24] H. Shiue, M. W. Musch, Y. Wang, E. B. Chang, and J. R. Turner, "Akt2 phosphorylates ezrin to trigger NHE3 translocation and activation," Journal of Biological Chemistry, vol. 280, no. 2, pp. 1688-1695, 2005.

[25] J. Klisic, M. C. Hu, V. Nief et al., "Insulin activates $\mathrm{Na}^{+} / \mathrm{H}^{+}$exchanger 3: biphasic response and glucocorticoid dependence," American Journal of Physiology, vol. 283, no. 3, pp. F532-F539, 2002.

[26] D. G. Fuster, I. A. Bobulescu, J. Zhang, J. Wade, and O. W. Moe, "Characterization of the regulation of renal $\mathrm{Na}^{+} / \mathrm{H}^{+}$ exchanger NHE3 by insulin," American Journal of Physiology, vol. 292, no. 2, pp. F577-F585, 2007.

[27] Z. Talor, D. S. Emmanouel, and A. I. Katz, "Insulin (INS) stimulates Na-K-ATPase activity of basolateral (BL) renal tubular membranes," Kidney International, vol. 21, supplement 1, p. 266, 1982.

[28] C. Rivera, H. Santos-Reyes, and M. Martinez-Maldonado, "Response of dog renal Na,K-ATPase to insulin in vitro," Renal Physiology, vol. 1, no. 2, pp. 74-83, 1978.

[29] E. Feraille, M. L. Carranza, M. Rousselot, and H. Favre, "Insulin enhances sodium sensitivity of Na-K-ATPase in isolated rat proximal convoluted tubule," American Journal of Physiology, vol. 267, no. 1, pp. F55-F62, 1994.

[30] O. S. Ruiz, YI. Y. Qiu, L. R. Cardoso, and J. A. L. Arruda, "Regulation of the renal $\mathrm{Na}-\mathrm{HCO}_{3}$ cotransporter: IX. Modulation by insulin, epidermal growth factor and carbachol," Regulatory Peptides, vol. 77, no. 1-3, pp. 155-161, 1998.

[31] K. A. Kirchner, "Insulin increases loop segment chloride reabsorption in the euglycemic rat," American Journal of Physiology, vol. 255, no. 6, pp. F1206-F1213, 1988.

[32] O. Ito, Y. Kondo, N. Takahashi et al., "Insulin stimulates $\mathrm{NaCl}$ transport in isolated perfused MTAL of Henle's loop of rabbit kidney," American Journal of Physiology, vol. 267, no. 2, pp. F265-F270, 1994.
[33] N. Takahashi, O. Ito, and K. Abe, "Tubular effects of insulin," Hypertension Research, vol. 19, no. 1, pp. S41-S45, 1996.

[34] M. Tsimaratos, F. Roger, D. Chabardès et al., "C-peptide stimulates $\mathrm{Na}^{+}, \mathrm{K}^{+}$-ATPase activity via $\mathrm{PKC}$ alpha in rat medullary thick ascending limb," Diabetologia, vol. 46, no. 1, pp. 124-131, 2003.

[35] J. Loffing and C. Korbmacher, "Regulated sodium transport in the renal connecting tubule (CNT) via the epithelial sodium channel (ENaC)," Pflugers Archiv, vol. 458, no. 1, pp. 111-135, 2009.

[36] B. L. Blazer-Yost, X. Liu, and S. I. Helman, "Hormonal regulation of eNaCs: insulin and aldosterone," American Journal of Physiology, vol. 274, no. 5, pp. C1373-C1379, 1998.

[37] E. Feraille, M. Rousselot, R. Rajerison, and H. Favre, "Effect of insulin on $\mathrm{Na}^{+}, \mathrm{K}^{+}$-ATPase in rat collecting duct," Journal of Physiology, vol. 488, no. 1, pp. 171-180, 1995.

[38] A. V. Chibalin, M. V. Kovalenko, J. W. Ryder, E. Féraille, H. Wallberg-Henriksson, and J. R. Zierath, "Insulin- and glucose-induced phosphorylation of the $\mathrm{Na}^{+}, \mathrm{K}^{+}$-adeno-sine triphosphatase $\alpha$-subunits in rat skeletal mescle," Endocrinology, vol. 142, no. 8, pp. 3474-3482, 2001.

[39] IL. H. Lee, C. R. Campbell, D. I. Cook, and A. Dinudom, "Regulation of epithelial $\mathrm{Na}^{+}$channels by aldosterone: role of Sgk1," Clinical and Experimental Pharmacology and Physiology, vol. 35, no. 2, pp. 235-241, 2008.

[40] J. Loffing, S. Y. Flores, and O. Staub, "Sgk kinases and their role in epithelial transport," Annual Review of Physiology, vol. 68, pp. 461-490, 2006.

[41] M. F. White, R. Maron, and C. R. Kahn, "Insulin rapidly stimulates tyrosine phosphorylation of a M(r)-185,000 protein in intact cells," Nature, vol. 318, no. 6042, pp. 183-186, 1985.

[42] X. J. Sun, P. Rothenberg, C. R. Kahn et al., "Structure of the insulin receptor substrate IRS-1 defines a unique signal transduction protein," Nature, vol. 352, no. 6330, pp. 73-77, 1991.

[43] X. J. Sun, L. M. Wang, Y. Zhang et al., "Role of IRS-2 in insulin and cytokine signalling," Nature, vol. 377, no. 6545, pp. 173-177, 1995.

[44] M. F. White, "The IRS-signalling system: a network of docking proteins that mediate insulin action," Molecular and Cellular Biochemistry, vol. 182, no. 1-2, pp. 3-11, 1998.

[45] J. C. Brüning, J. Winnay, B. Cheatham, and C. R. Kahn, "Differential signaling by insulin receptor substrate 1 (IRS-1) and IRS- 2 in IRS-1-deficient cells," Molecular and Cellular Biology, vol. 17, no. 3, pp. 1513-1521, 1997.

[46] E. Araki, M. A. Lipes, M. E. Patti et al., "Alternative pathway of insulin signalling in mice with targeted disruption of the IRS-1 gene," Nature, vol. 372, no. 6502, pp. 186-190, 1994.

[47] N. Kubota, K. Tobe, Y. Terauchi et al., "Disruption of insulin receptor substrate 2 causes type 2 diabetes because of liver insulin resistance and lack of compensatory $\beta$-cell hyperplasia," Diabetes, vol. 49, no. 11, pp. 1880-1889, 2000.

[48] Y. Kido, D. J. Burks, D. Withers et al., "Tissue-specific insulin resistance in mice with mutations in the insulin receptor, IRS-1, and IRS-2," Journal of Clinical Investigation, vol. 105, no. 2, pp. 199-205, 2000.

[49] Y. Zheng, H. Yamada, K. Sakamoto et al., "Roles of insulin receptor substrates in insulin-induced stimulation of renal proximal bicarbonate absorption," Journal of the American Society of Nephrology, vol. 16, no. 8, pp. 2288-2295, 2005. 
[50] L. J. Goodyear, F. Giorgino, L. A. Sherman, J. Carey, R. J. Smith, and G. L. Dohm, "Insulin receptor phosphorylation, insulin receptor substrate-1 phosphorylation, and phosphatidylinositol 3-kinase activity are decreased in intact skeletal muscle strips from obese subjects," Journal of Clinical Investigation, vol. 95, no. 5, pp. 2195-2204, 1995.

[51] J. E. Friedman, T. Ishizuka, J. Shao, L. Huston, T. Highman, and P. Catalano, "Impaired glucose transport and insulin receptor tyrosine phosphorylation in skeletal muscle from obese women with gestational diabetes," Diabetes, vol. 48, no. 9, pp. 1807-1814, 1999.

[52] C. M. Rondinone, L. M. Wang, P. Lonnroth, C. Wesslau, J. H. Pierce, and U. Smith, "Insulin receptor substrate (IRS) 1 is reduced and IRS-2 is the main docking protein for phosphatidylinositol 3-kinase in adipocytes from subjects with non-insulin-dependent diabetes mellitus," Proceedings of the National Academy of Sciences of the United States of America, vol. 94, no. 8, pp. 4171-4175, 1997.

[53] E. Carvalho, P. A. Jansson, M. Axelsen et al., "Low cellular IRS 1 gene and protein expression predict insulin resistance and NIDDM," FASEB Journal, vol. 13, no. 15, pp. 2173-2178, 1999.

[54] N. M. Al-Rasheed, G. B. Willars, and N. J. Brunskill, "Cpeptide signals via $\mathrm{G} \alpha$ to protect against TNF- $\alpha$-mediated apoptosis of opossum kidney proximal tubular cells," Journal of the American Society of Nephrology, vol. 17, no. 4, pp. 986-995, 2006.

[55] H. Wajant, K. Pfizenmaier, and P. Scheurich, "Tumor necrosis factor signaling," Cell Death and Differentiation, vol. 10, no. 1, pp. 45-65, 2003.

[56] P. Peraldi and B. Spiegelman, "TNF- $\alpha$ and insulin resistance: summary and future prospects," Molecular and Cellular Biochemistry, vol. 182, no. 1-2, pp. 169-175, 1998.

[57] G. S. Hotamisligil, "The role of TNF $\alpha$ and TNF receptors in obesity and insulin resistance," Journal of Internal Medicine, vol. 245, no. 6, pp. 621-625, 1999.

[58] K. T. Uysal, S. M. Wiesbrock, M. W. Marino, and G. S. Hotamisligil, "Protection from obesity-induced insulin resistance in mice lacking TNF- $\alpha$ function," Nature, vol. 389, no. 6651, pp. 610-614, 1997.

[59] S. E. Shoelson, J. Lee, and A. B. Goldfine, "Inflammation and insulin resistance," Journal of Clinical Investigation, vol. 116, no. 7, pp. 1793-1801, 2006.

[60] MD. R. Amin, J. Malakooti, R. Sandoval, P. K. Dudeja, and K. Ramaswamy, "IFN- $\gamma$ and TNF- $\alpha$ regulate human NHE3 gene expression by modulating the $\mathrm{Sp}$ family transcription factors in human intestinal epithelial cell line C2BBe1," American Journal of Physiology, vol. 291, no. 5, pp. C887-C896, 2006.

[61] M. D. R. Amin, P. K. Dudeja, K. Ramaswamy, and J. Malakooti, "Involvement of Sp1 and Sp3 in differential regulation of human NHE3 promoter activity by sodium butyrate and IFN- $\gamma$ /TNF- $\alpha$, American Journal of Physiology, vol. 293, no. 1, pp. G374-G382, 2007.

[62] M. Shahid, J. Francis, and D. S. A. Majid, "Tumor necrosis factor- $\alpha$ induces renal vasoconstriction as well as natriuresis in mice," American Journal of Physiology, vol. 295, no. 6, pp. F1836-F1844, 2008.

[63] K. DiPetrillo, B. Coutermarsh, and F. A. Gesek, "Urinary tumor necrosis factor contributes to sodium retention and renal hypertrophy during diabetes," American Journal of Physiology, vol. 284, no. 1, pp. F113-F121, 2003.
[64] K. DiPetrillo, B. Coutermarsh, N. Soucy, J. Hwa, and F. Gesek, "Tumor necrosis factor induces sodium retention in diabetic rats through sequential effects on distal tubule cells," Kidney International, vol. 65, no. 5, pp. 1676-1683, 2004.

[65] C. Schmidt, K. Höcherl, F. Schweda, A. Kurtz, and M. Bucher, "Regulation of renal sodium transporters during severe inflammation," Journal of the American Society of Nephrology, vol. 18, no. 4, pp. 1072-1083, 2007.

[66] A. D. M. Riquier-Brison, P. K. K. Leong, K. Pihakaski-Maunsbach, and A. A. McDonough, "Angiotensin II stimulates trafficking of NHE3, NaPi2, and associated proteins into the proximal tubule microvilli," American Journal of Physiology, vol. 298, no. 1, pp. F177-F186, 2010.

[67] F. A. El-Atat, S. N. Stas, S. I. Mcfarlane, and J. R. Sowers, "The relationship between hyperinsulinemia, hypertension and progressive renal disease," Journal of the American Society of Nephrology, vol. 15, no. 11, pp. 2816-2827, 2004.

[68] L. A. Velloso, F. Folli, L. Perego, and M. J. A. Saad, "The multi-faceted cross-talk between the insulin and angiotensin II signaling systems," Diabetes/Metabolism Research and Reviews, vol. 22, no. 2, pp. 98-107, 2006.

[69] G. Lastra, S. Dhuper, M. S. Johnson, and J. R. Sowers, "Salt, aldosterone, and insulin resistance: impact on the cardiovascular system," Nature Reviews Cardiology, vol. 7, no. 10, pp. 577-584, 2010.

[70] S. Horita, Y. Zheng, C. Hara et al., "Biphasic regulation of $\mathrm{Na}^{+}-\mathrm{HCO}_{3}^{-}$cotransporter by angiotensin II type $1 \mathrm{~A}$ receptor," Hypertension, vol. 40, no. 5, pp. 707-712, 2002.

[71] Y. Zheng, S. Horita, C. Hara et al., "Biphasic regulation of renal proximal bicarbonate absorption by luminal AT receptor," Journal of the American Society of Nephrology, vol. 14, no. 5, pp. 1116-1122, 2003.

[72] Y. Li, H. Yamada, Y. Kita et al., "Roles of ERK and cPLA in the angiotensin II-mediated biphasic regulation of $\mathrm{Na}^{+}-\mathrm{HCO}_{3}^{-}$ transport," Journal of the American Society of Nephrology, vol. 19, no. 2, pp. 252-259, 2008.

[73] S. L. Zhang, X. Chen, T. J. Hsieh et al., "Hyperglycemia induces insulin resistance on angiotensinogen gene expression in diabetic rat kidney proximal tubular cells," Journal of Endocrinology, vol. 172, no. 2, pp. 333-344, 2002.

[74] B. E. Xu, J. M. English, J. L. Wilsbacher, S. Stippec, E. J. Goldsmith, and M. H. Cobb, "WNK1, a novel mammalian serine/threonine protein kinase lacking the catalytic lysine in subdomain II," Journal of Biological Chemistry, vol. 275, no. 22, pp. 16795-16801, 2000.

[75] F. H. Wilson, S. Disse-Nicodème, K. A. Choate et al., "Human hypertension caused by mutations in WNK kinases," Science, vol. 293, no. 5532, pp. 1107-1112, 2001.

[76] J. A. McCormick, C. L. Yang, and D. H. Ellison, "WNK kinases and renal sodium transport in health and disease: an integrated view," Hypertension, vol. 51, no. 3, pp. 588-596, 2008.

[77] M. E. Safar and H. S. Boudier, "Vascular development, pulse pressure, and the mechanisms of hypertension," Hypertension, vol. 46, no. 1, pp. 205-209, 2005.

[78] C. L. Yang, J. Angell, R. Mitchell, and D. H. Ellison, "WNK kinases regulate thiazide-sensitive $\mathrm{Na}-\mathrm{Cl}$ cotransport," Journal of Clinical Investigation, vol. 111, no. 7, pp. 1039-1045, 2003.

[79] A. P. Golbang, G. Cope, A. Hamad et al., "Regulation of the expression of the $\mathrm{Na} / \mathrm{Cl}$ cotransporter by WNK4 and WNK1: evidence that accelerated dynamin-dependent endocytosis is not involved," American Journal of Physiology, vol. 291, no. 6, pp. F1369-F1376, 2006. 
[80] H. Cai, V. Cebotaru, Y. H. Wang et al., "WNK4 kinase regulates surface expression of the human sodium chloride cotransporter in mammalian cells," Kidney International, vol. 69, no. 12, pp. 2162-2170, 2006.

[81] A. Ohta, T. Rai, N. Yui et al., "Targeted disruption of the Wnk4 gene decreases phosphorylation of $\mathrm{Na}-\mathrm{Cl}$ cotransporter, increases $\mathrm{Na}$ excretion and lowers blood pressure," Human Molecular Genetics, vol. 18, no. 20, pp. 3978-3986, 2009.

[82] C. L. Yang, X. Zhu, Z. Wang, A. R. Subramanya, and D. H. Ellison, "Mechanisms of WNK1 and WNK4 interaction in the regulation of thiazide-sensitive $\mathrm{NaCl}$ cotransport," Journal of Clinical Investigation, vol. 115, no. 5, pp. 1379-1387, 2005.

[83] A. R. Subramanya, C. L. Yang, X. Zhu, and D. H. Ellison, "Dominant-negative regulation of WNK1 by its kidneyspecific kinase-defective isoform," American Journal of Physiology, vol. 290, no. 3, pp. F619-F624, 2006.

[84] J. Rinehart, K. T. Kahle, P. De Los Heros et al., "WNK3 kinase is a positive regulator of NKCC2 and NCC, renal cation-Cl cotransporters required for normal blood pressure homeostasis," Proceedings of the National Academy of Sciences of the United States of America, vol. 102, no. 46, pp. 1677716782, 2005.

[85] C. L. Yang, X. Zhu, and D. H. Ellison, "The thiazide-sensitive $\mathrm{Na}-\mathrm{Cl}$ cotransporter is regulated by a WNK kinase signaling complex," Journal of Clinical Investigation, vol. 117, no. 11, pp. 3403-3411, 2007.

[86] C. J. Heise, B.-E. Xu, S. L. Deaton et al., "Serum and Glucocorticoid-induced Kinase (SGK) 1 and the epithelial sodium channel are regulated by multiple with no lysine (WNK) family members," Journal of Biological Chemistry, vol. 285, no. 33, pp. 25161-25167, 2010.

[87] A. C. Vitari, M. Deak, B. J. Collins et al., "WNK1, the kinase mutated in an inherited high-blood-pressure syndrome, is a novel PKB (protein kinase B)/Akt substrate," Biochemical Journal, vol. 378, no. 1, pp. 257-268, 2004.

[88] E. Sohara, T. Rai, A. Ohta, e. Ohta, S. Sasaki, and S. Uchida, "Novel Insulin-WNK4-NCC phosphorylation cascade is involved in pathogenesis of PHA II caused by WNK4 R1185C mutation," in Proceedings of the 42nd Annual Meeting of American Society of Nephrology, p. F-FC279, San Diego, Calif, USA, November 2009.

[89] D. H. Ellison, T. T. Oyama, C. L. Yang, S. Rogers, D. r. Beard, and R. Komers, "Altered WNK4/NCC signaling in a rat model of insulin resistance," in Proceedings of the 42nd Annual Meeting of American Society of Nephrology, p. SA-FC432, November 2009.

[90] C. L. Huang and E. Kuo, "Mechanisms of Disease: WNK-ing at the mechanism of salt-sensitive hypertension," Nature Clinical Practice Nephrology, vol. 3, no. 11, pp. 623-630, 2007.

[91] E. J. Hoorn, N. Van Der Lubbe, and R. Zietse, "The renal WNK kinase pathway: a new link to hypertension," Nephrology Dialysis Transplantation, vol. 24, no. 4, pp. 1074-1077, 2009. 


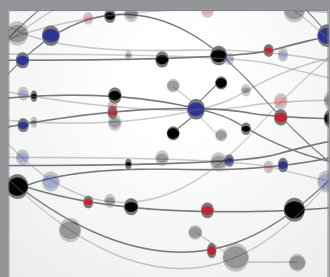

The Scientific World Journal
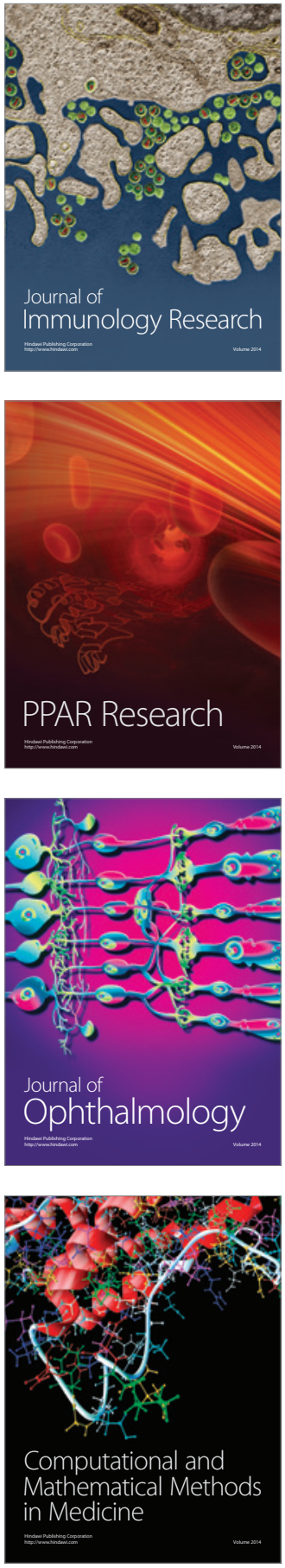

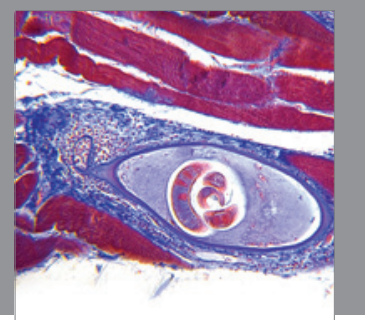

Gastroenterology

Research and Practice
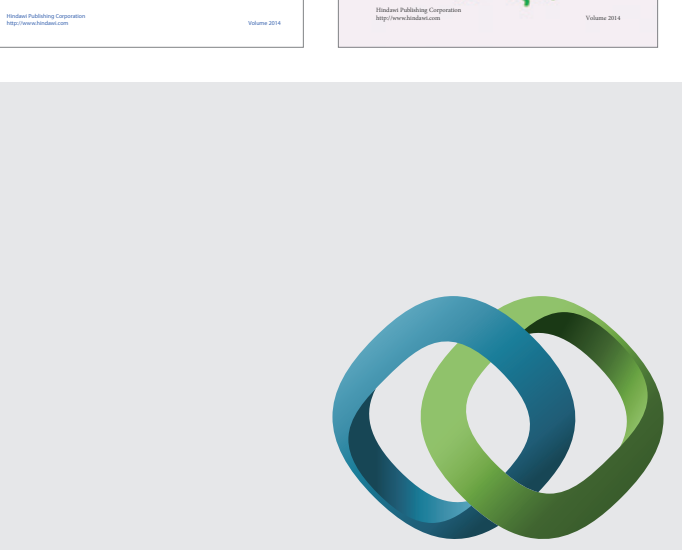

\section{Hindawi}

Submit your manuscripts at

http://www.hindawi.com
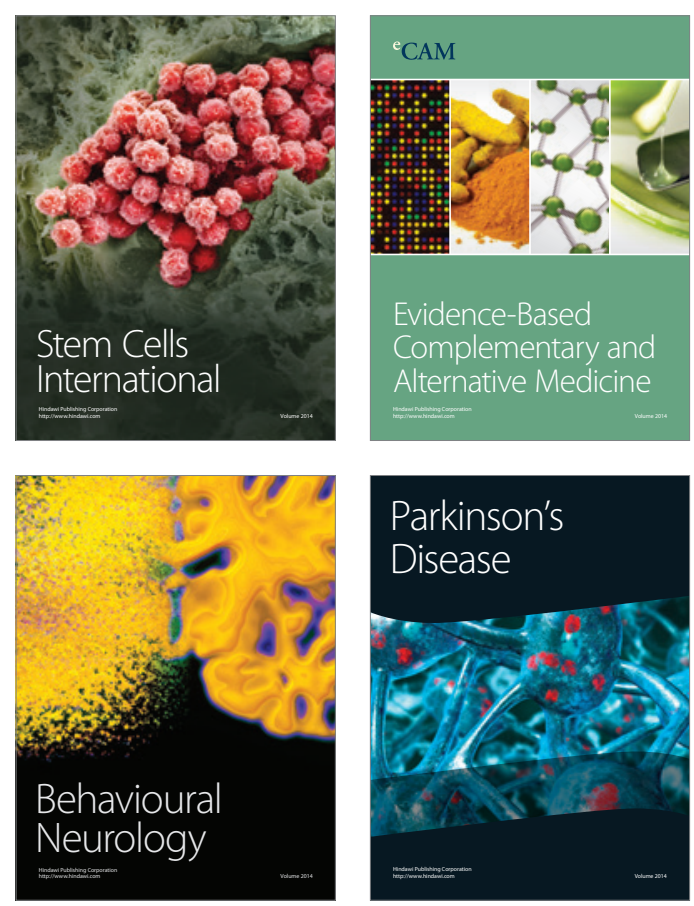

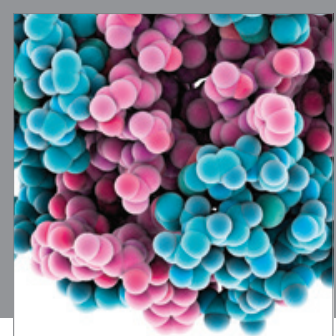

Journal of
Diabetes Research

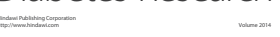

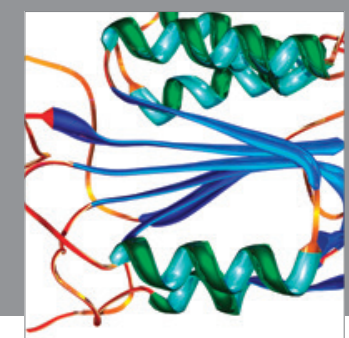

Disease Markers
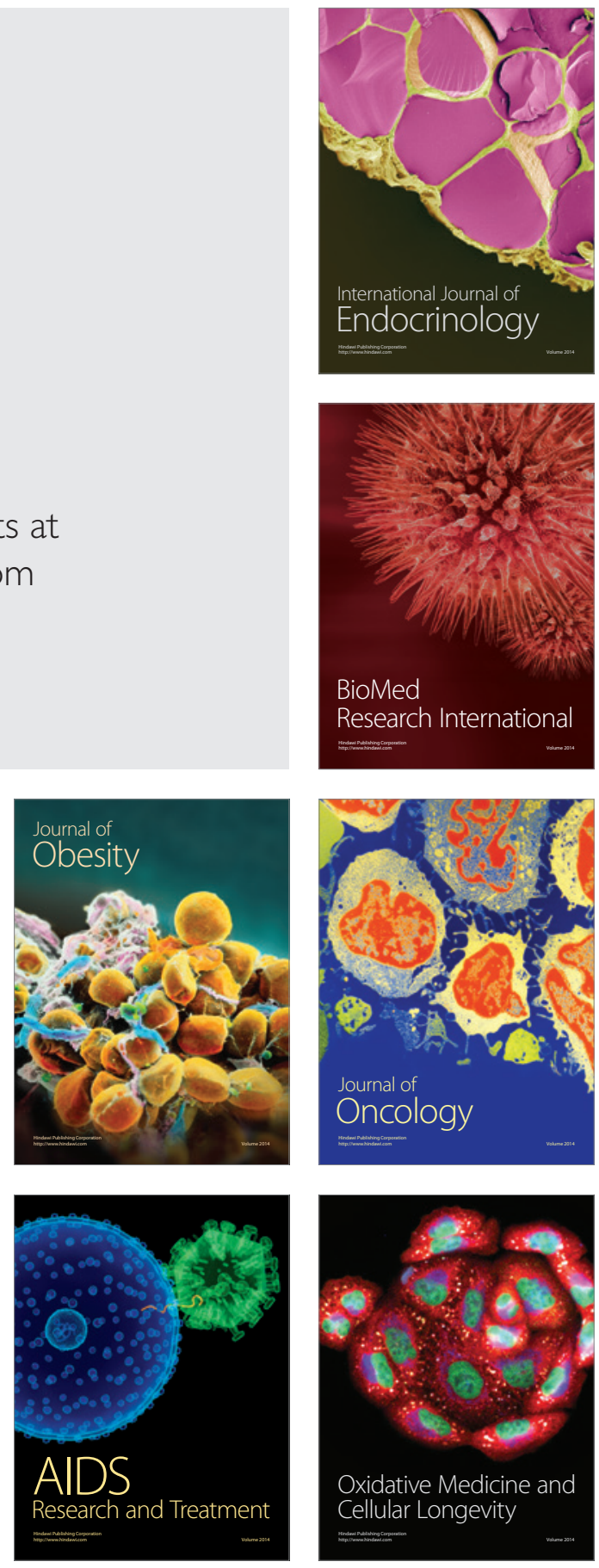